Maarsingh, O.R., Dros, J., Windt, D.A. van der, Riet, G. ter, Schellevis, F.G., Weert, H.C. van, Horst, H.E. van der. Diagnostic indicators of anxiety and depression in older dizzy patients in primary care. Journal of Geriatric Psychiatry and Neurology: 2011, 24(2), 98-107

\begin{tabular}{|l|l|}
\hline Postprint Version & 1.0 \\
\hline Journal website & http://jgp.sagepub.com/content/24/2/98.long \\
\hline Pubmed link & http://www.ncbi.nlm.nih.gov/pubmed/21546650 \\
\hline DOI & $10.1177 / 0891988711405332$ \\
\hline
\end{tabular}

This is a NIVEL certified Post Print, more info at http://www.nivel.eu

\title{
Diagnostic Indicators of Anxiety and Depression in Older Dizzy Patients in Primary Care
}

OTTO R. MAARSINGH, MD, PHD ${ }^{1}$, JACQUELIEN DROS, MD², DANIE“" LLE A. VAN DER WINDT, PHD ${ }^{3}$, GERBEN TER RIET, MD, PHD ${ }^{2}$, FRANC, OIS G. SCHELlEVIS, MD, PHD ${ }^{1,4}$, HENK C. VAN WEERT, MD, PHD ${ }^{2}$, AND HENRIE“TTE E. VAN DER HORST, MD, PHD ${ }^{1}$

${ }^{1}$ Department of Family Practice and EMGO Institute for Health and Care Research, VU University Medical Center, Amsterdam, Netherlands ${ }^{2}$ Department of Family Practice, Academic Medical Center, University of Amsterdam, Netherlands ${ }^{3}$ Arthritis Research UK National Primary Care Centre, Keele University,

Staffordshire, UK ${ }^{4}$ NIVEL, the Netherlands Institute for Health Services Research, Utrecht, Netherlands

\begin{abstract}
Background: Dizzy patients with both psychological and physical symptoms tend to have high levels of disability and are at risk of remaining symptomatic and disabled. The objective of this study was to develop a prediction model for the presence of anxiety and/or depression in older dizzy patients in primary care. Methods: We performed a cross-sectional study among 415 older patients consulting their primary care physician for persistent dizziness. Participants underwent a standardized, comprehensive evaluation and completed self-administered questionnaires regarding anxiety and depression (PRIME-MD Patient Health Questionnaire [PHQ]) and dizziness-related disability (Dizziness Handicap Inventory). To determine the diagnostic indicators of anxiety and/or depression, we used multiple logistic regression analysis with "presence of Panic Disorder, Other Anxiety Disorder, or Major Depressive Disorder"' as dependent variable. Potential diagnostic indicators included dizziness-related disability, patient characteristics (age, sex, history of anxiety, and history of depression), and dizziness characteristics (description of dizziness, provoking circumstances, associated symptoms, onset, frequency, duration, and avoidance of activities because of dizziness). Results: According to the PHQ, an anxiety and/or depressive disorder was present in 90 patients (22\%), of whom 35 reported no medical history of anxiety or depression, nor current pharmacological treatment for these disorders. In the final model, dizziness-related disability, a history of depression, and accompanying fear were associated with an increased odd of anxiety and/or depression, whereas tinnitus and rotational dizziness were associated with a decreased odd of anxiety and/or depression. The model showed good calibration (Hosmer-Lemeshow $\mathrm{P}$ value of .46) and discrimination (adjusted area under the receiver operating characteristic curve [AUC] after bootstrapping of .82). Conclusions: Primary care physicians should consider the existence of anxiety and depression in older patients presenting with dizziness. After external validation, our model may contribute to better recognition and hence better management of anxiety and depression in older patients with dizziness in primary care.
\end{abstract}

\section{INTRODUCTION}

Dizziness is a common symptom, especially in older patients. 
Maarsingh, O.R., Dros, J., Windt, D.A. van der, Riet, G. ter, Schellevis, F.G., Weert, H.C. van, Horst, H.E. van def. Diagnostic indicators of anxiety and depression in older dizzy patients in primary care. Journal of Geriatric Psychiatry and Neurology: 2011, 24(2), 98-107

Thirty percent of the people older than 65 years experience dizziness in some form, ${ }^{1-4}$ increasing to $50 \%$ in the very old (85p). ${ }^{2}$ Almost $10 \%$ of persons aged 65 years or older visit their primary care physician at least once a year because of dizziness.

${ }^{5}$ Dizziness can be caused by a wide range of conditions, including vestibular, cardiovascular, neurological, metabolic, and psychiatric diseases. ${ }^{6}$ Often, dizziness has more than one cause. ${ }^{7-9}$ In $15 \%$ to $40 \%$ of dizzy patients in primary care, psychiatric disorders, especially anxiety or depression, may play a causative or contributory role. ${ }^{8-11}$ Compared to those without psychiatric disorders, dizzy patients with psychiatric disorders tend to have higher levels of self-perceived disability ${ }^{10,12,13}$ are more likely to remain symptomatic and disabled, ${ }^{14-16}$ and use more dizziness-related health care ${ }^{17}$ Therefore, recognition of anxiety or depressive disorders in patientswith dizziness is of great importance, especially because the number of patients with undetected anxiety or depression may be high, ${ }^{18-21}$ and these disorders can be treated effectively. ${ }^{22,23}$ Until now, only few studies have reported on indicators of anxiety or depression in a dizzy population. ${ }^{10,12,24,25}$ However, none of these studies included a population representative of patients seen in a primary care setting. The objective of this study was to develop a prediction model for the presence of anxiety and/or depression in older patients presenting with dizziness in primary care.

\section{METHODS}

\section{Setting and Patients}

Participants were recruited among consecutive patients seen by 45 primary care physicians in 24 family practices in the Netherlands. In all, 22 practices did form part of a research network, 2 practices did not form part of a research network but previously participated in primary care research. Patients aged 65 years or older consulting their primary care physician for dizziness that had been present for at least 2 weeks were invited to participate. Additionally, each month the electronic databases of all practices were searched retrospectively for any dizzy patients the primary care physicians had failed to invite (see Appendix A). These patients received a written invitation to participate in the study. We obtained written informed consent from all participants. Our definition of dizziness included a giddy or rotational sensation, loss of balance, feeling faint, light-headedness, instability or unsteadiness, a tendency to fall, or the sensation of everything turning black. Criteria for exclusion were the inability to speak Dutch or English, severe cognitive impairment, severe visual impairment, severe hearing impairment, or wheelchair dependency. Patients were enrolled from June 2006 to January 2008, and the study protocol was approved by the Medical Ethics Committee of the VU University Medical Center.

\section{Presence of Anxiety or Depression}

All patients were asked to complete the Anxiety and Mood module of the PRIME-MD Patient Health Questionnaire (PHQ), an instrument to establish the presence of psychiatric disorders based on the Diagnostic and Statistical Manual of Mental Disorders, Fourth Edition (DSM-IV) criteria. ${ }^{26,27}$ Using the PHQ algorithm, we determined for each patient the presence or absence of the diagnoses panic disorder (PD), other anxiety disorder (OAD), and major depressive disorder (MDD).

The diagnostic algorithm for PD consists of 15 questions with 2 answer categories (yes or no) and is considered fulfilled if the answer to questions 3a-d is "yes" and if the answer to 4 or more of questions 4a$\mathrm{k}$ is " "yes." ${ }^{27}$ The diagnostic algorithm for OAD consists of 7 questions with 2 answer categories (yes or no) and is considered fulfilled if the answer to question $5 \mathrm{a}$ is "yes" and if the answer to 3 or more of questions 5b-g is "yes." ${ }^{27}$ The diagnostic algorithm for MDD consists of 9 questions with 4 answer categories (not at all, several days, more than half the days, and nearly every day) and is considered fulfilled if the answer to questions $2 \mathrm{a}$ and $2 \mathrm{~b}$ and 5 or more of questions $2 \mathrm{a}-2 \mathrm{i}$ is at least "more than half the days" (question $2 \mathrm{i}$ is counted if present at all). ${ }^{27}$ The diagnostic algorithms of the PHQ have been shown to have good criterion validity with reference to gold standard measures of mental disorders. ${ }^{27-30}$ Studied in primary care populations, sensitivity and specificity of the PHQ for PD were $75 \%$ to $81 \%$ and $96 \%$ to $99 \%$, respectively ${ }^{27,28}$ In a metaanalysis, Wittkampf et al reported pooled estimates of sensitivity and specificity of the PHQ for MDD in primary care populations were $80 \%$ and $92 \%$, respectively. ${ }^{31}$ Studied in a dizzy population, sensitivity and specificity of the PHQ for any anxiety disorder (PD or OAD) were $94 \%$ and 95\%; sensitivity and specificity of the PHQforMDDwere 69\%and 94\%, respectively. ${ }^{32}$ Until now, only few studies have examined the reliability of the PHQ, reporting moderate-to-high inter-rater reliability (any anxiety disorder: $\mathrm{k}^{1 / 4} .55-.83$; MDD: $\mathrm{k}^{1 / 4} .61-.65$ ) ${ }^{26,32}$ and moderateto- satisfactory test-retest reliability (any anxiety disorder: $\mathrm{k}^{1 / 4}$.51; MDD: $\left.\mathrm{k} 1 / 4.58-.69\right) .{ }^{33,34}$ Potential Diagnostic Indicators 
Maarsingh, O.R., Dros, J., Windt, D.A. van der, Riet, G. ter, Schellevis, F.G., Weert, H.C. van, Horst, H.E. van der. Diagnostic indicators of anxiety and depression in older dizzy patients in primary care. Journal of Geriatric Psychiatry and Neurology: 2011, 24(2), 98-107

All participants underwent a standardized, comprehensive evaluation based on a set of diagnostic tests that we developed during an international Delphi procedure. ${ }^{35,36}$ We used a system for computer-assisted survey processing (Blaise 4.7) to create a standardized interview setting and to avoid missing data.

Potential diagnostic indicators included patient characteristics (age, sex, history of anxiety, and history of depression), and dizziness characteristics (description of dizziness, provoking circumstances, associated symptoms, onset, frequency, duration, and avoidance of activities because of dizziness). We also asked the participants to complete the Dizziness Handicap Inventory (DHI), a 25-item questionnaire with 3 answer categories (yes, sometimes, or no) developed to study self-perceived physical, emotional, and functional disability associated with dizziness. ${ }^{37}$ Using the algorithm of the DHI, we calculated for each patient the total level of dizziness-related disability (maximum score of 100) ${ }^{37}$ We wanted to develop a prediction model based on the first part of the diagnostic process, because during this part of the diagnostic process the clinician still has to decide on additional diagnostic "tools." Therefore, we did not use the results of physical examination or additional diagnostic testing as a source for candidate diagnostic indicators.

\section{Statistical Analysis}

The data were analyzed in SPSS for Windows, version 15.0.1.

To develop a prediction model for the identification of anxiety and depression, we performed multiple logistic regression analysis with "presence (or absence) of PD, OAD, or MDD"' as dependent variable. Prior to regression analysis, we assessed the univariable association between each indicator and the outcome with binary logistic regression analysis to reduce the number of potential diagnostic indicators. Variables were only entered into the multivariable regression model if the univariable $\mathrm{P}$ value was $<.2$. We tested continuous variables for linear association with the outcome, which revealed no nonlinear associations. In a subsequent backward elimination process (Wald test), we deleted variables from the initial model until only variables with a $\mathrm{P}$ value of $<.157$ (Akaike Information Criterion) were retained in the final model. ${ }^{38}$

\section{[FIGURE 1]}

\section{Performance of the model.}

The reliability of the model was quantified with the Hosmer-Lemeshow goodness-of-fit statistics.

${ }^{39}$ The calibration of the model was assessed by plotting the predicted probabilities against the observed frequencies of anxiety and/or depression. ${ }^{40}$ For this assessment, patients were grouped into deciles according to their predicted probability.

The prevalence of the outcome measure within each decile equals the observed frequency. If the predicted probabilities and the observed frequencies are in agreement, the estimates are close to the diagonal.

The discriminative ability of the model (ie, its ability to distinguish dizzy patients with anxiety and/or depression from dizzy patients without anxiety and/or depression) was assessed by calculating the area under the receiver-operating characteristic curve (AUC). An AUC of 0.5 indicates no discrimination above chance, whereas an AUC of 1.0 indicates perfect discrimination. ${ }^{40}$ Prediction models perform better in the development cohort than in other similar populations. After multiple logistic regression analysis, we used a bootstrapping procedure to adjust for this overoptimism in model performance. ${ }^{40,41}$ Bootstrap samples were drawn with replacement (n $1 / 4$ 500) from the full data set and were used to compute an adjusted AUC. This adjusted AUC provides a more precise estimate of the performance of the model in similar, future patients. The bootstrapping procedure was performed in R statistical software, version 2.6.0.

\section{RESULTS}

During the study period, 415 patients underwent the standardized evaluation (Figure 1). Patient characteristics and results of the PHQ are summarized in Table 1. An anxiety and/or depressive disorder was present in 90 patients with dizziness (22\%). Of these 90 patients, 35 patients reported no medical history of anxiety or depression, nor current pharmacological treatment for these disorders. An anxiety and depressive disorder was present in 21 patients (5\%), of whom 6 reported no medical history of anxiety or depression, nor current pharmacological treatment for these disorders. 
Maarsingh, O.R., Dros, J., Windt, D.A. van der, Riet, G. ter, Schellevis, F.G., Weert, H.C. van, Horst, H.E. van der. Diagnostic indicators of anxiety and depression in older dizzy patients in primary care. Journal of Geriatric Psychiatry and Neurology: 2011, 24(2), 98-107

\section{[TABLE 1]}

\section{Indicators of an Anxiety or Depressive Disorder}

Table 2 summarizes the univariable associations of all potential diagnostic indicators with the outcome. After the backward elimination procedure, the multivariable model included 9 diagnostic indicators. In order to reduce the number of diagnostic indicators (and to improve the clinical usefulness of our model), we performed a second backward elimination procedure with a lower $\mathrm{P}$ value $(<.02)$, which resulted in a final multivariable model including 5 diagnostic indicators (Table 3).

Dizziness-related disability (a higher score on the DHI) was associated with an increased odds of anxiety and/or depression, fear as an associated symptom during an episode of dizziness, and a history of depression. Tinnitus during an episode of dizziness, and dizziness described as a rotational sensation were associated with a decreased odd of anxiety and/or depression.

Using the model, the prior probability of 22\% (90 of 415) of current anxiety and/or depression could be reduced to a posterior probability of at best $0.4 \%$ in people with low scores for all predictors (lowest value; low DHI score, no associated fear or history of depression, presence of tinnitus, and rotational dizziness) or 96\% in people with high scores (highest value; high DHI score, presence of associated fear and history of depression, no tinnitus, and rotational dizziness).

\section{Performance of the Model}

According to the Hosmer-Lemeshow statistic, the reliability of the model was adequate (P value of .46). Figure 2 shows the calibration of the predictions. The predicted and observed probabilities are close to the 45_line, demonstrating good calibration of the predictions by the model. The discriminative ability of the model was good (AUC1/40.83 [0.79-0.88]), also after adjustment for overoptimism (adjusted AUC 1/4 0.82; optimism $1 / 4$ 0.009).

\section{DISCUSSION}

\section{Summary of Main Findings}

In this cross-sectional study performed among consecutive dizzy primary care patients aged 65 or older, an anxiety and/or depressive disorder was present in $22 \%$ of the patients. In the final model, dizzinessrelated disability, fear as an associated symptom during an episode of dizziness, and a history of depression were associated with an increased odd of anxiety and/or depression. Tinnitus during an episode of dizziness and dizziness described as a rotational sensation were associated with a decreased odd of anxiety and/or depression. The model showed good calibration and discrimination (also after adjustment for overoptimism).

\section{Comparison With Existing Literature}

Until now, only few studies have reported on indicators of anxiety or depression in a dizzy population. However, none of these studies included a population representative of patients seen in a primary care setting. ${ }^{10,12,24,25}$ Moreover, no other study reported dizziness-related disability to be such a strong diagnostic indicator of anxiety or depression, although several studies did find an association between functional impairment and psychiatric disease. . $^{10,12,24}$

\section{[TABLE 2]}

In 2 studies, it was found that dizziness provoked by hyperventilation was an independent predictor of psychiatric disease in patients with dizziness. ${ }^{10,25}$ We were not able to study this potential diagnostic indicator, because hyperventilation testing was not included in the standardized evaluation, as established by our expert panel. ${ }^{35}$ Kroenke et al reported age below 40 years, related complaints of weakness or headaches, and dizziness provoked by standing to be independent predictors of psychiatric disorders in patients with dizziness. ${ }^{10}$ This different set of predictors may be the result of a difference in the age of the study population (mean age 62 years, range 20-85 years vs mean age 79 years, range 65-95 years) and a difference in the study setting (hospital vs family practice).

In a study performed among patients in a geriatric dizziness clinic, Sloane et al reported onset of dizziness by fatigue as a predictor of a psychiatric diagnosis. ${ }^{25}$ Unfortunately, our standardized evaluation did not include the assessment of fatigue, ${ }^{35}$ so we were unable to determine whether this could be an important indicator of anxiety or depression in our population. 
Maarsingh, O.R., Dros, J., Windt, D.A. van der, Riet, G. ter, Schellevis, F.G., Weert, H.C. van, Horst, H.E. van def. Diagnostic indicators of anxiety and depression in older dizzy patients in primary care. Journal of Geriatric Psychiatry and Neurology: 2011, 24(2), 98-107

\section{[TABLE 3]}

\section{[FIGURE 2]}

Our finding of tinnitus and rotational dizziness being associated with the absence of anxiety or depression may be explained by the fact that tinnitus and rotational dizziness are typically vestibular symptoms, that is dizzy patients with such symptoms have a high probability of a vestibular-and not psychiatric — cause of dizziness. ${ }^{42}$ In our study, approximately two fifths of the dizzy patients with an anxiety and/or depressive disorder according to the PHQ, and almost one third of the dizzy patients with both an anxiety and a depressive disorder reported no medical history of anxiety or depression, nor current pharmacological treatment for these disorders. Although it is tempting to conclude that our data suggest insufficient recognition of anxiety and depression by primary care physicians, ${ }^{18-21}$ we emphasize that the above definition (ie, "diagnosis of anxiety or depression according to the PHQ, but no reported history of anxiety or depression and no reported pharmacological treatment for anxiety or depression’”) is a suboptimal measure for underdetection and lacks additional information, for example about underreporting, refusal of therapy, current nonpharmacological treatment, or false-positive diagnoses according to the PHQ.

\section{Strengths and Limitations of This Study}

To our knowledge, we are the first to develop a prediction model for the presence of anxiety and/or depression in older dizzy patients in primary care. One of the strengths of this study is the selection of the study population, which is highly representative of primary care. This is partly due to the monthly database search to identify all eligible patients, thus including also patients the primary care physicians had not invited. ${ }^{9}$ This procedure reduced the risk of recruiting a selective sample of patients. Another strength is the absence of missing values in a relatively large sample, limiting loss of statistical power and possible bias. ${ }^{43}$ Some limitations of our study should be mentioned. First, the use of questionnaires to determine the presence of anxiety and/or depression - instead of gold standard clinical interviews for mental disorderscould be regarded a limitation. However, the operating characteristics of the PHQ for PD or OAD in a dizzy population are excellent (sensitivity 94\%, specificity 95\%, positive predictive value [PPV] $80 \%$, and negative predictive value [NPV] 99\%). ${ }^{32}$ The operating characteristics of the PHQ for MDD are only satisfactory, both in the primary care populations (pooled estimates of sensitivity and specificity $80 \%-81 \%$ and $92 \%$, respectively) ${ }^{31,44}$ and in a dizzy population (sensitivity $69 \%$, specificity $94 \%$, PPV 73\%, and NPV $94 \%) .{ }^{32}$ However, we accepted this, because the operating characteristics of the PHQ for MDD are still superior to those of several other instruments that are commonly used to assess depression, such as the PHQ-9 (cutoff score), the Hospital Anxiety and Depression Scale (HADS), and the WHO Well-Being Index 5 (WBI-5). ${ }^{29,30,45}$ Second, the number of cases in our study was relatively small compared to the number of potential predictors.

Although the exact sample size calculations for prediction models do not exist, the general rule is that for each candidate predictor there should be at least 10 events (1:10 rule).$^{46} \mathrm{We}$ had 20 candidate predictors with 90 cases (ratio 1:5). When a limited number of positive cases are available, statistical methods such as bootstrapping can be used to estimate the potential effects of sampling variation on the predictive performance of a model. ${ }^{46}$ The bootstrapping procedure only revealed a small reduction in the AUC (from 0.83 to 0.82 ; optimism 0.009 ), suggesting good internal validity of our final model. However, external validation in a new population is needed to confirm the performance of our model and its transportability to other populations of older dizzy primary care patients. ${ }^{47}$ Finally, it could be argued that the use of the DHI is not feasible in daily clinical practice. However, completing the DHI takes relatively little time (approximately 10 minutes) and can be done prior to consultation. ${ }^{37}$ Alternatively, clinicians can use a shorter version of the DHI (10 items instead of 25), ${ }^{48}$ which has an almost equally strong association with the presence of anxiety and/or depression (additional analysis; results can be obtained from the corresponding author).

\section{Implications for Clinical Practice and Further Research}

Primary care physicians should consider the presence of anxiety and depression in older patients with dizziness, especially because patients with both psychological and physical symptoms tend to have a worse prognosis, ${ }^{14-16}$ and effective treatment is available. ${ }^{22,23}$ Hopefully, our prediction model will lead to a diagnostic decision rule that improves the recognition of anxiety and depression in older dizzy primary care patients. The necessary steps toward an applicable and useful decision rule include (1) external validation in a new dizzy population, ${ }^{47}(2)$ development of a score chart to facilitate the calculation of an individual 
Maarsingh, O.R., Dros, J., Windt, D.A. van der, Riet, G. ter, Schellevis, F.G., Weert, H.C. van, Horst, H.E. van def. Diagnostic indicators of anxiety and depression in older dizzy patients in primary care. Journal of Geriatric Psychiatry and Neurology: 2011, 24(2), 98-107

patient's risk, ${ }^{49}$ and, perhaps most importantly, (3) investigation of the ability of the decision rule to influence medical decision making and to improve relevant outcomes in older patients with dizziness. ${ }^{50}$

\section{CONCLUSION}

In our final model, dizziness-related disability, a history of depression, and accompanying fear were associated with the presence of anxiety and/or depression in older dizzy patients in primary care, whereas tinnitus and rotational dizziness were associated with the absence of anxiety or depression. After external validation, our model may contribute to better recognition and management of anxiety and depression in older dizzy patients in primary care.

\section{ACKNOWLEDGEMENT}

The authors thank David Vergouw for his help with the bootstrapping procedure.

\section{AUTHORs' Note}

HvdH and HvW obtained funding for the study. OM, JD, DvdW, GtR, FS, HvW, and HvdH were involved in the design of the study. OM performed the statistical analysis and wrote the original draft. All authors critically revised the draft with regard to important intellectual content and approved the final version.

Support

\section{DECLARATION OF CONFLICTING INTERESTS}

The authors declared no conflicts of interest with respect to the authorship and/or publication of this article.

\section{FUNDING}

The authors disclosed receipt of the following financial support for the research and/or authorship of this article: supported by the Netherlands Organisation for Health Research and Development (ZonMW, No. 4200.0018), The Hague. The sponsor did not participate in the study design, data-collection, analysis, interpretation, or the preparation or submission of this report.

\section{[APPENDIX A]}

\section{REFERENCES}

1. Colledge NR, Wilson JA, Macintyre CC, MacLennan WJ.

The prevalence and characteristics of dizziness in an elderly community. Age Ageing. 1994;23(2):117-120.

2. Jonsson R, Sixt E, Landahl S, Rosenhall U. Prevalence of dizziness and vertigo in an urban elderly population. J Vestib Res.

2004;14(1):47-52.

3. Sloane P, Blazer D, George LK. Dizziness in a community elderly population. J Am Geriatr Soc. 1989;37(2):101-108.

4. Tinetti ME, Williams CS, Gill TM. Dizziness among older adults: a possible geriatric syndrome. Ann Intern Med. 2000;132(5): 337-344.

5. Maarsingh OR, Dros J, Schellevis FG, van Weert HC, Bindels PJ, Van der Horst HE. Dizziness reported by elderly patients in family practice: prevalence, incidence, and clinical characteristics.

BMC Fam Pract. 2010;11(1):2.

6. Sloane PD, Coeytaux RR, Beck RS, Dallara J. Dizziness: state of the science. Ann Intern Med.

2001;134(9 Pt 2):823-832.

7. Colledge NR, Barr-Hamilton RM, Lewis SJ, Sellar RJ, Wilson JA. Evaluation of investigations to diagnose the cause of dizziness in elderly people: a community based controlled study. BMJ. 1996;313(7060):788-792.

8. Kroenke K, Lucas CA, Rosenberg ML, et al. Causes of persistent dizziness. A prospective study of 100 patients in ambulatory care.

Ann Intern Med. 1992;117(11):898-904. 
Maarsingh, O.R., Dros, J., Windt, D.A. van der, Riet, G. ter, Schellevis, F.G., Weert, H.C. van, Horst, H.E. van der. Diagnostic indicators of anxiety and depression in older dizzy patients in primary care. Journal of Geriatric Psychiatry and Neurology: 2011, 24(2), 98-107

9. Maarsingh OR, Dros J, Schellevis FG, et al. Causes of persistent dizziness in elderly patients in primary care: a diagnostic study based on panel diagnosis. Ann Fam Med. 2010;(8):196-205.

10. Kroenke K, Lucas CA, Rosenberg ML, Scherokman BJ. Psychiatric disorders and functional impairment in patients with persistent dizziness. J Gen Intern Med. 1993;8(10):530-535.

11. Sloane PD, Dallara J, Roach C, Bailey KE, Mitchell M, McNutt R. Management of dizziness in primary care. J Am Board Fam Pract. 1994;7(1):1-8.

12. Eckhardt-Henn A, Breuer P, Thomalske C, Hoffmann SO, Hopf HC. Anxiety disorders and other psychiatric subgroups in patients complaining of dizziness. J Anxiety Dis. 2003;17(4): 369-388.

13. Yardley L, Owen N, Nazareth I, Luxon L. Prevalence and presentation of dizziness in a general practice community sample of working age people. Br J Gen Pract. 1998;48(429):1131-1135.

14. Bailey KE, Sloane PD, Mitchell M, Preisser J. Which primary care patients with dizziness will develop persistent impairment? Arch Fam Med. 1993;2(8):847-852.

15. Yardley L. Overview of psychologic effects of chronic dizziness and balance disorders. Otolaryngol Clin North Am. 2000;33(3): 603-616.

16. Kroenke K, Lucas C, Rosenberg ML, Scherokman B, Herbers JE.

One-year outcome for patients with a chief complaint of dizziness.

J Gen Intern Med. 1994;9(12):684-689.

17. Wiltink J, Tschan R, Michal M, et al. Dizziness: anxiety, health care utilization and health behaviorresults from a representative German community survey. J Psychosom Res. 2009; 66(5):417-424.

18. Kessler D, Bennewith O, Lewis G, Sharp D. Detection of depression and anxiety in primary care: follow up study. BMJ.

2002;325(7371):1016-1017.

19. Kroenke K, Spitzer RL, Williams JB, Monahan PO, Lowe B.

Anxiety disorders in primary care: prevalence, impairment, comorbidity, and detection. Ann Intern Med. 2007;146(5):317-325.

20. Licht-Strunk E, Beekman AT, de Haan M, van Marwijk HW.

The prognosis of undetected depression in older general practice patients. A one year follow-up study. $\mathrm{J}$

Affect Disord.

2009;114(1-3):310-315.

21. Kessler D, Lloyd K, Lewis G, Gray DP. Cross sectional study of symptom attribution and recognition of depression and anxiety in primary care. BMJ. 1999;318(7181):436-439.

22. Westen D, Morrison K. A multidimensional meta-analysis of treatments for depression, panic, and generalized anxiety disorder: an empirical examination of the status of empirically supported therapies. $\mathrm{J}$ Consult Clin Psychol. 2001;69(6):875-899.

23. Whooley MA, Simon GE. Managing depression in medical outpatients. N Engl J Med. 2000;343(26):1942-1950.

24. Piker EG, Jacobson GP, McCaslin DL, Grantham SL. Psychological comorbidities and their relationship to self-reported handicap in samples of dizzy patients. J Am Acad Audiol. 2008;19(4): 337-347.

25. Sloane PD, Hartman M, Mitchell CM. Psychological factors associated with chronic dizziness in patients aged 60 and older.

J Am Geriatr Soc. 1994;42(8):847-852.

26. Spitzer RL, Williams JB, Kroenke K, et al. Utility of a new procedure for diagnosing mental disorders in primary care. The PRIME-MD 1000 study. JAMA. 1994;272(22):1749-1756.

27. Spitzer RL, Kroenke K, Williams JB. Validation and utility of a self-report version of PRIME-MD: the PHQ primary care study.

Primary Care Evaluation of Mental Disorders. Patient Health Questionnaire. JAMA. 1999;282(18):17371744.

28. Lowe B, Grafe K, Zipfel S, et al. Detecting panic disorder in medical and psychosomatic outpatients: comparative validation of the Hospital Anxiety and Depression Scale, the Patient Health Questionnaire, a screening question, and physicians' diagnosis.

J Psychosom Res. 2003;55(6):515-519.

29. Lowe B, Spitzer RL, Grafe K, et al. Comparative validity of three screening questionnaires for DSM-IV depressive disorders and physicians' diagnoses. J Affect Disord. 2004;78(2): 131-140.

30. Lowe B, Grafe K, Zipfel S, Witte S, Loerch B, Herzog W.

Diagnosing ICD-10 depressive episodes: superior criterion validity of the Patient Health Questionnaire.

Psychother Psychosom.

2004;73(6):386-390.

31. Wittkampf KA, Naeije L, Schene AH, Huyser J, van Weert HC.

Diagnostic accuracy of the mood module of the Patient Health Questionnaire: a systematic review. Gen

Hosp Psychiatry.

2007;29(5):388-395. 
Maarsingh, O.R., Dros, J., Windt, D.A. van der, Riet, G. ter, Schellevis, F.G., Weert, H.C. van, Horst, H.E. van def. Diagnostic indicators of anxiety and depression in older dizzy patients in primary care. Journal of Geriatric Psychiatry and Neurology: 2011, 24(2), 98-107

32. Persoons P, Luyckx K, Desloovere C, Vandenberghe J, Fischler B. Anxiety and mood disorders in otorhinolaryngology outpatients presenting with dizziness: validation of the selfadministered PRIME-MD Patient Health Questionnaire and epidemiology. Gen Hosp Psychiatry. 2003;25(5):316-323.

33. Bakker IM, Terluin B, van Marwijk HW, van Mechelen W, Stalman WA. Test-retest reliability of the PRIME-MD: limitations in diagnosing mental disorders in primary care. Eur J Public Health. 2009;19(3):303-307.

34. Lamers F, Jonkers CC, Bosma H, Penninx BW, Knottnerus JA, van Eijk JT. Summed score of the Patient Health Questionnaire-9 was a reliable and valid method for depression screening in chronically ill elderly patients. J Clin Epidemiol. 2008;61(7):679-687.

35. Maarsingh OR, Dros J, van Weert HC, Schellevis FG, Bindels PJ, Van der Horst HE. Development of a diagnostic protocol for dizziness in elderly patients in general practice: a Delphi procedure.

BMC Family Practice. 2009;10:12.

36. Dros J, Maarsingh OR, Van der Horst HE, Bindels PJ, ter Riet G, van Weert HC. Tests used to diagnose dizziness in primary care.

CMAJ. 2010;182(13): E621-E631.

37. Jacobson GP, Newman CW. The development of the Dizziness Handicap Inventory. Arch Otolaryngol Head Neck Surg.

1990;116(4):424-427.

38. Altman DG. Practical Statistics for Medical Research. London: Chapman and Hall; 1991.

39. Hosmer DW, Lemeshow S. Applied Logistic Regression. New York: John Wiley \& Sons; 1989:135-175.

40. Harrell FE Jr, Lee KL, Mark DB. Multivariable prognostic models: issues in developing models,

evaluating assumptions and adequacy, and measuring and reducing errors. Stat Med.

1996;15(4):361-387.

41. Steyerberg EW, Bleeker SE, Moll HA, Grobbee DE, Moons KG.

Internal and external validation of predictive models: a simulation study of bias and precision in small samples. J Clin Epidemiol.

2003;56(5):441-447.

42. Okkes IM, Oskam SK, Lamberts H. From Complaint to Diagnosis. Episode Data from Family Practice.

Bussum, The Netherlands: Coutinho; 1998.

43. Vergouwe $Y$, Royston P, Moons KG, Altman DG. Development and validation of a prediction model with missing predictor data: a practical approach. J Clin Epidemiol. 2010;63(2):205-214.

44. Gilbody S, Richards D, Brealey S, Hewitt C. Screening for depression in medical settings with the Patient Health Questionnaire (PHQ): a diagnostic meta-analysis. J Gen Intern Med.

2007;22(11):1596-1602.

45. Stafford L, Berk M, Jackson HJ. Validity of the Hospital Anxiety and Depression Scale and Patient Health Questionnaire-9 to screen for depression in patients with coronary artery disease. Gen Hosp Psychiatry. 2007;29(5):417-424.

46. Peduzzi P, Concato J, Kemper E, Holford TR, Feinstein AR.

A simulation study of the number of events per variable in logistic regression analysis. $\mathrm{J}$ Clin Epidemiol. 1996;49(12):1373-1379.

47. Justice AC, Covinsky KE, Berlin JA. Assessing the generalizability of prognostic information. Ann Intern Med.

1999;130(6):515-524.

48. Jacobson GP, Calder JH. A screening version of the Dizziness Handicap Inventory (DHI-S). Am J Otol. 1998;19(6): 804-808.

49. Kuijpers T, van der Windt DA, Boeke AJ, et al. Clinical prediction rules for the prognosis of shoulder pain in general practice. Pain. 2006;120(3):276-285.

50. Vergouwe Y, Steyerberg EW, Eijkemans MJ, Habbema JD.

Validity of prognostic models: when is a model clinically useful? Semin Urol Oncol. 2002;20(2):96-107. 
Maarsingh, O.R., Dros, J., Windt, D.A. van der, Riet, G. ter, Schellevis, F.G., Weert, H.C. van, Horst, H.E. van der. Diagnostic indicators of anxiety and depression in older dizzy patients in primary care. Journal of Geriatric

\section{TABLES AND FIGURES}

\section{Figure 1}

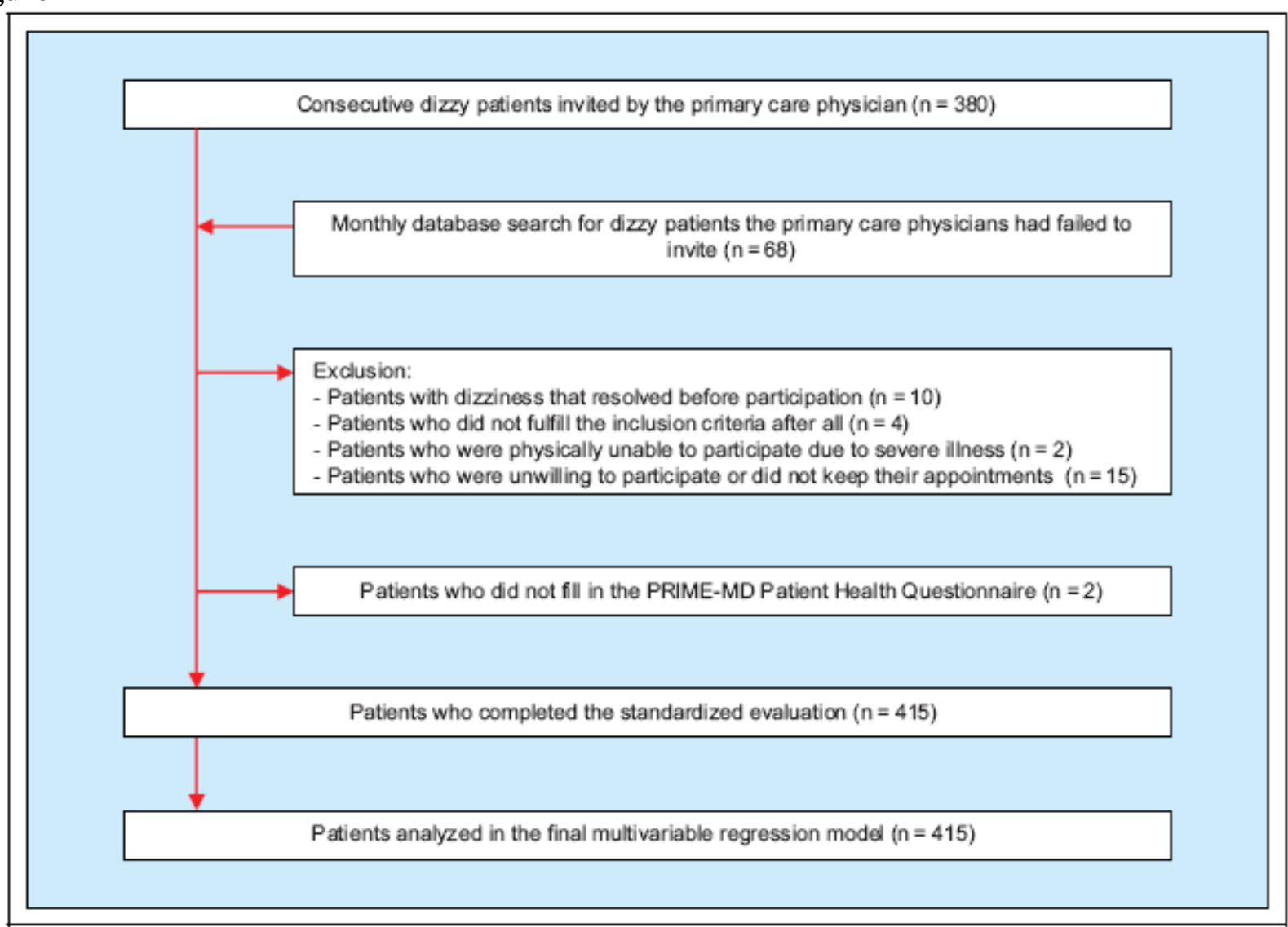

Figure I. Flowchart of participants through the study.

Table 1 
Maarsingh, O.R., Dros, J., Windt, D.A. van der, Riet, G. ter, Schellevis, F.G., Weert, H.C. van, Horst, H.E. van der. Diagnostic indicators of anxiety and depression in older dizzy patients in primary care. Journal of Geriatric Psychiatry and Neurology: 2011, 24(2), 98-107

Table I. Patient Characteristics and Results of Psychiatric Testing of 415 Older Dizzy Primary Care Patients*

\begin{tabular}{|c|c|}
\hline $\begin{array}{l}\text { Patient Charocteristics } \\
\text { Gender, female }\end{array}$ & $305(73)$ \\
\hline Age in years, mean $\pm S D$ & $78.5 \pm 7.2$ \\
\hline \multicolumn{2}{|l|}{ Living situation } \\
\hline Alone & $252(61)$ \\
\hline Home for the elderly, or other institution & $66(16)$ \\
\hline \multicolumn{2}{|l|}{ Ethnic background } \\
\hline Dutch native & $341(82)$ \\
\hline Western immigrant & 44 (II) \\
\hline Non-Western immigrant & $30(7)$ \\
\hline \multicolumn{2}{|l|}{ Level of education } \\
\hline Elementary school & $117(28)$ \\
\hline High school & $247(60)$ \\
\hline College/university & $51(12)$ \\
\hline \multicolumn{2}{|l|}{ Drugs, total } \\
\hline Number of drugs per patient, mean $\pm S D$ & $4.4 \pm 3.0$ \\
\hline Major polypharmacy (patients using $>5$ drugs) & $137(33)$ \\
\hline \multicolumn{2}{|l|}{ Medical history } \\
\hline $\begin{array}{l}\text { Number of chronic disorders, mean } \pm \text { SD } \\
\text { Cardiovascular disease }\end{array}$ & $3.5 \pm 1.9$ \\
\hline Hypertension & $237(57)$ \\
\hline Ischemic heart disease & $109(26)$ \\
\hline Arrythmia & $94(23)$ \\
\hline Heart valve disease & $57(14)$ \\
\hline Myocardial infarction & $56(13)$ \\
\hline \multicolumn{2}{|l|}{ Ear, nose, and throat disease } \\
\hline Benign paroxysmal positional dizziness & $40(10)$ \\
\hline Ménière disease & $27(7)$ \\
\hline \multicolumn{2}{|l|}{ Neurological disease } \\
\hline Migraine & $79(19)$ \\
\hline Cerebrovascular disease & $65(16)$ \\
\hline Parkinson disease & $7(2)$ \\
\hline Epilepsia & $6(1)$ \\
\hline \multicolumn{2}{|l|}{ Locomotor disease } \\
\hline Gonarthrosis & $120(29)$ \\
\hline Coxarthrosis & $78(19)$ \\
\hline \multicolumn{2}{|l|}{ Psychiatric disease } \\
\hline $\begin{array}{l}\text { Depressive disorder } \\
\text { Anxiety disorder }\end{array}$ & $\begin{array}{l}101(24) \\
75(18)\end{array}$ \\
\hline \multicolumn{2}{|l|}{ Other } \\
\hline Cataract & $198(48)$ \\
\hline Diabetes & $76(18)$ \\
\hline Macular degeneration & $27(7)$ \\
\hline \multicolumn{2}{|l|}{ Psychiatric diagnosis according to the PRIME-MD PHQ } \\
\hline \multicolumn{2}{|l|}{ Anxiety disorder } \\
\hline Panic disorder & $19(5)$ \\
\hline Other anxiety disorder & $39(9)$ \\
\hline \multicolumn{2}{|l|}{ Depressive disorder } \\
\hline Major depressive disorder & $53(13)$ \\
\hline Anxiety or depressive disorder (or both) & $90(22)$ \\
\hline Anxiety and depressive disorder & $21(5)$ \\
\hline
\end{tabular}

Abbreviations: PHQ, Patient Health Questionnaire; SD, standard deviation.

* Values are the number (percentage) unless otherwise indicated. 
Maarsingh, O.R., Dros, J., Windt, D.A. van der, Riet, G. ter, Schellevis, F.G., Weert, H.C. van, Horst, H.E. van def. Diagnostic indicators of anxiety and depression in older dizzy patients in primary care. Journal of Geriatric Psychiatry and Neurology: 2011, 24(2), 98-107

Table 2

Table 2. Univariable Associations of Patient and Dizziness Characteristics With the Presence (or Absence) of an Anxiety and/or Depressive Disorder*

\begin{tabular}{|c|c|c|c|c|}
\hline Variable & $\begin{array}{l}\text { Anxiety and/or Depressive } \\
\text { Disorder: } \mathrm{YES}^{\dagger}(\mathrm{n}=90)\end{array}$ & $\begin{array}{l}\text { Anxiety and/or Depressive } \\
\text { Disorder. } \mathrm{NO}^{\dagger}(\mathrm{n}=325)\end{array}$ & OR $(95 \% \mathrm{Cl})^{ \pm}$ & $\begin{array}{c}P \\
\text { Value }\end{array}$ \\
\hline \multicolumn{5}{|l|}{ A. Patient characteristics } \\
\hline Age (years), mean $\pm S D$ & $80.0 \pm 6.9$ & $78.1 \pm 7.2$ & $1.04(1.01-1.07)$ & .025 \\
\hline Female sex & $72(80)$ & $233(72)$ & $1.6(0.9-2.8)$ & .116 \\
\hline Anxiety disorder in medical history & $28(31)$ & 47 (15) & $2.7(1.6-4.6)$ & $<.001$ \\
\hline Depressive disorder in medical history & $36(40)$ & $65(20)$ & $2.7(1.6-4.4)$ & $<.001$ \\
\hline \multicolumn{5}{|l|}{ B. Dizziness characteristics } \\
\hline \multicolumn{5}{|l|}{ Description } \\
\hline Light-headedness & $55(61)$ & $192(59)$ & I.I (0.7-1.8) & .728 \\
\hline Rotational sensation & $42(47)$ & $186(57)$ & $0.7(0.4-1.0)$ & .076 \\
\hline Environment spinning & $30(33)$ & $107(33)$ & $1.0(0.6-1.7)$ & .942 \\
\hline Near faint & $24(27)$ & $72(22)$ & $1.3(0.7-2.2)$ & .370 \\
\hline Everything turning black & $12(13)$ & $56(17)$ & $0.7(0.4-1.4)$ & .378 \\
\hline Giddy & $48(53)$ & $128(39)$ & $1.8(1.1-2.8)$ & .019 \\
\hline Loss of balance & $63(70)$ & $217(67)$ & I.I $(0.7-1.9)$ & .563 \\
\hline Instability or unstea diness & $72(80)$ & $215(66)$ & $2.0(1.2-3.6)$ & .013 \\
\hline \multicolumn{5}{|l|}{ Provoking circumstances of dizziness } \\
\hline Standing still & $36(40)$ & $62(19)$ & $2.8(1.7-4.7)$ & $<.001$ \\
\hline Exercise & $38(42)$ & $90(28)$ & $1.9(1.2-3.1)$ & .009 \\
\hline Turning head & $53(59)$ & $170(52)$ & $1.3(0.8-2.1)$ & .269 \\
\hline Bending forward & $63(70)$ & $190(59)$ & $1.7(1.0-2.7)$ & .048 \\
\hline Looking up & $51(57)$ & $163(50)$ & $1.3(0.8-2.1)$ & .275 \\
\hline Strong emotions & $26(29)$ & $53(16)$ & $2.1(1.2-3.6)$ & .008 \\
\hline $\begin{array}{l}\text { Getting up from a lying or sitting } \\
\text { position }\end{array}$ & $68(76)$ & $223(69)$ & $1.4(0.8-2.4)$ & .204 \\
\hline \multicolumn{5}{|c|}{ Associated symptoms during the episode of dizziness } \\
\hline Nausea & $26(29)$ & $85(26)$ & I.I (0.7-1.9) & .604 \\
\hline Sweaty, pale, or clammy & $23(26)$ & $67(21)$ & $1.3(0.8-2.3)$ & .315 \\
\hline Hearing problems & $5(6)$ & $19(6)$ & $0.9(0.3-2.6)$ & .917 \\
\hline Tinnitus & $5(6)$ & 37 (II) & $0.5(0.2-1.2)$ & .112 \\
\hline Palpitations or chest pain & $19(21)$ & $39(12)$ & $2.0(1.1-3.6)$ & .029 \\
\hline Dyspnoea & $18(20)$ & $30(9)$ & $2.5(1.3-4.7)$ & .006 \\
\hline $\begin{array}{l}\text { Diplopia or difficulty with speaking/ } \\
\text { swallowing }\end{array}$ & $10(11)$ & $29(9)$ & $1.3(0.6-2.7)$ & .530 \\
\hline Fear & $33(37)$ & $50(15)$ & $3.2(1.9-5.4)$ & $<.001$ \\
\hline Tendency to fall & 64 (7I) & 143 (44) & $3.1(1.9-5.2)$ & $<.001$ \\
\hline Onset of dizziness: less than I month & $I(1)$ & $28(9)$ & $0.1(0.02-0.9)$ & .038 \\
\hline Frequency of dizziness: continuous & $15(17)$ & $26(8)$ & $2.3(1.2-4.6)$ & .017 \\
\hline $\begin{array}{l}\text { Duration of dizziness episode: more than } \\
60 \text { seconds }\end{array}$ & $60(67)$ & $167(51)$ & $1.9(1.2-3.1)$ & .011 \\
\hline $\begin{array}{l}\text { Score of Dizziness Handicap Inventory }(0 \text { - } \\
100) \text {, mean } \pm S D\end{array}$ & $51.8 \pm 18.0$ & $32.0 \pm 18.2$ & $1.06(1.04-1.07)$ & $<.001$ \\
\hline
\end{tabular}

* Values are the number (percentage) unless otherwise indicated.

'Diagnosis of "Panic Disorder, Other Anxiety Disorder, and/or Major Depressive Disorder," according to the PRIME-MD PHQ.

† Binary logistic regression analysis.

Table 3

Table 3. Diagnostic Indicators of Anxiety and/or Depression in 415 Older Dizzy Primary Care Patients*

\begin{tabular}{|c|c|c|c|c|c|}
\hline Indicator & B & Wald & OR & $95 \% \mathrm{Cl}$ & $P$ value \\
\hline \multicolumn{6}{|l|}{ Patient characteristics } \\
\hline Depressive disorder in medical history & 0.884 & 8.7 & 2.4 & $1.3-4.3$ & .003 \\
\hline \multicolumn{6}{|l|}{ Dizziness characteristics } \\
\hline Description of dizziness: rotational sensation & -0.757 & 6.9 & 0.5 & $0.3-0.8$ & .008 \\
\hline Associated symptom during episode of dizziness: tinnitus & -1.584 & 7.7 & 0.2 & $0.1-0.6$ & .005 \\
\hline Associated symptom during episode of dizziness: fear & 1.027 & 10.4 & 2.8 & $1.5-5.2$ & .001 \\
\hline Score of Dizziness Handicap Inventory (0-100, in steps of 10$)$ & 0.583 & 52.5 & 1.8 & $1.5-2.1$ & $<.001$ \\
\hline
\end{tabular}

Abbreviations: Cl, confidence interval; OR, odds ratio.

* Dependent variable "diagnosis of Panic Disorder, Other Anxiety Disorder, or Major Depressive Disorder, according to the PRIME-MD Patient Health

Questionnaire," $\mathrm{AUC} 0.83, \mathrm{Cl}=0.79-0.88$, adjusted $\mathrm{AUC}=0.82$, and optimism $=0.009$. 
Maarsingh, O.R., Dros, J., Windt, D.A. van der, Riet, G. ter, Schellevis, F.G., Weert, H.C. van, Horst, H.E. van def. Diagnostic indicators of anxiety and depression in older dizzy patients in primary care. Journal of Geriatric Psychiatry and Neurology: 2011, 24(2), 98-107

\section{Figure 2}

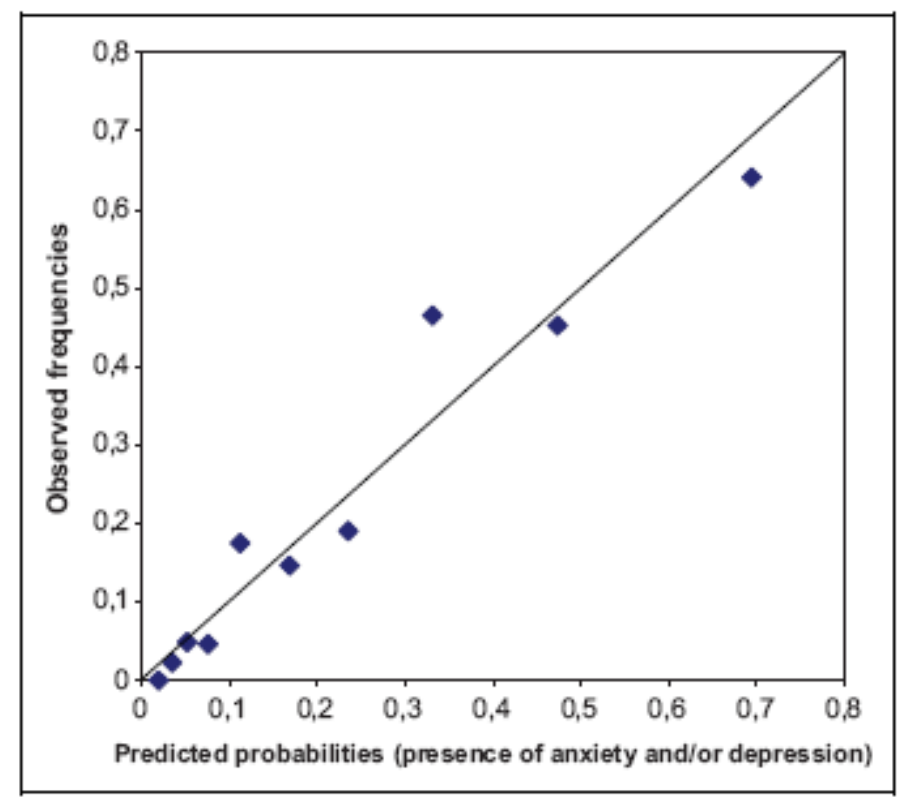

Figure 2. Calibration plot showing the observed frequencies versus the predicted probabilities for patients with anxiety and/or depression.

\section{Appendix A}

Table AI. Search Strategy Used in Electronic Databases for Identifying Dizzy Patients the Primary Care Physicians had Failed to Invite ( 15 search terms and 3 ICPC codes)

\begin{tabular}{|c|c|c|c|c|}
\hline A. Search Terms & Symptom in Dutch & English transhation & Dizziness subtype & Type of Sensation \\
\hline $\begin{array}{l}\text { I. draai }{ }^{2} \\
\text { 2. vertig } \\
\text { 3. zweve }\end{array}$ & $\begin{array}{l}\text { - draaierig } \\
\text { - vertigo } \\
\text { - zweverig }\end{array}$ & $\begin{array}{l}\text { - } \text { giddy/rotational } \\
\text { sensation } \\
\text { - vertigo } \\
- \text { giddy }\end{array}$ & I. Vertigo & $\begin{array}{l}\text { A feeling that one or one's } \\
\text { surroundings are } \\
\text { moving }\end{array}$ \\
\hline $\begin{array}{l}\text { 4. collab } \\
\text { 5. collap } \\
\text { 6. flauw } \\
\text { 7. licht in } \\
\text { 8. onwel } \\
\text { 9. zwart voor }\end{array}$ & $\begin{array}{l}\text { - collaberen } \\
\text { - collaps } \\
\text { - flauwte } \\
\text { - licht in het hoofd } \\
\text { - onwelwording } \\
\text { - zwart voor de ogen }\end{array}$ & $\begin{aligned} \text { - } & \text { collapsing } \\
\text { - } & \text { collapse } \\
\text { - } & \text { faint feeling } \\
\text { - } & \text { light-headedness } \\
- & \text { becoming unwell } \\
- & \text { everything turning } \\
& \text { black }\end{aligned}$ & II. Presyncope & $\begin{array}{l}\text { A lightheaded, faint feeling, } \\
\text { as though one were } \\
\text { about to pass out }\end{array}$ \\
\hline $\begin{array}{l}\text { 10. evenwicht }{ }^{2} \\
\text { II. onvast } \\
\text { I2. valnei } \\
\text { 13. wankel }\end{array}$ & $\begin{array}{l}\text { - evenwichtsstoornis } \\
\text { - onvast (ter been) } \\
\text { - valneiging } \\
\text { - } \text { wankel (ter been) }\end{array}$ & $\begin{array}{l}\text { - loss of equilibrium } \\
- \text { instability } \\
- \text { tendency to fall } \\
-\quad \text { to be unsteady on } \\
\text { one's legs }\end{array}$ & III. Disequilibrium & $\begin{array}{l}\text { A sense of unsteadiness } \\
\text { that is (1) primarily felt } \\
\text { in the lower } \\
\text { extremities, (2) most } \\
\text { prominent when } \\
\text { standing or walking, and } \\
\text { (3) relieved by sitting or } \\
\text { lying down }\end{array}$ \\
\hline $\begin{array}{l}\text { 14.dizz }{ }^{2} \\
\text { |5.duizel }\end{array}$ & $\begin{array}{l}\text { - dizzy } \\
\text { - duizeligheid }\end{array}$ & $\begin{array}{ll}\text { - dizy } \\
\text { - dizziness }\end{array}$ & IV. No subtype & Dizziness not specified \\
\hline $\begin{array}{l}\text { B. ICPC codes } \\
\text { I. A06 Fainting/sy! } \\
\text { 2. H82 Vertigin } \\
\text { 3. NI7 Vertigo/ }\end{array}$ & & & & \\
\hline
\end{tabular}

Abbreviation: ICPC, International Classification of Primary Care.

"Truncated search term. 